\title{
Descolonizando Narrativas:
}

\section{Uma análise epistemológica das narrativas sobre a participação das mulheres na primavera árabe}

\section{Ariane Torres Facci ${ }^{1}$}

\section{Resumo}

Este artigo pretende fazer uma análise epistemológica sobre a construção de narrativas acerca da participação das mulheres na chamada "Primavera Árabe", com foco específico no caso do Egito. Ilustramos como tais narrativas foram utilizadas tanto em meios acadêmicos como midiáticos para afirmar que estava ocorrendo uma luta pela democracia liberal, apoiando-se, sobretudo, no papel das mulheres nesses protestos. Assim, analisamos como as narrativas se bebem em divisões dicotômicas e epistemologias eurocêntricas, tão comum na Ciência, que dão espaço para novas colonialidades e, por isso, o caminho para uma análise profunda sobre o papel dessas mulheres nos levantes populares deve se dar por intermédio de uma reflexão epistemológica feminista decolonial. A partir disso, percorremos como tais narrativas são construídas para reforçar imaginários comuns de divisão entre Ocidente e Oriente, apropriando-se das mulheres árabes para aludir à luta pela democracia, denominando-as como protagonistas (para reafirmar o caráter democrático) ou como vítimas (da falta dessa mesma democracia). Por fim, concluímos que tais discursos minam o movimento feminista, anulando a agência dessas mulheres e reforçando instituições patriarcais.

\section{Palavras-chave: Mulheres - Primavera Árabe - Egito - Epistemologia Feminista Decolonial.}

\footnotetext{
${ }^{1}$ Graduanda em Relações Internacionais na Pontifícia Universidade Católica de São Paulo. Este artigo é resultado do trabalho de conclusão de curso realizado na PUC-SP sob a orientação da Prof ${ }^{a}$ Dr- Elaini C. G. da Silva. Email: arianefacci@outlook.com.br.
} 


\section{Abstract}

This paper aims to do an epistemological analysis of the constructions of narratives about the role of women in the so-called "Arab Spring", with a focus on the Egyptian case. We illustrate how these narratives were used in both academic and media circles to claim that a struggle for liberal democracy was taking place, relying mainly on the role of women in these protests. Thus, we analyze how they are built on dichotomic and epistemological divisions, common on science, that open space to new colonialities and, because of that, the path to a deep analysis on the role of these women in the popular uprisings must be carried out through a decolonial feminist epistemological reflection. From this, we explore how such narratives are constructed to reinforce common imaginaries of the division between the West and East, appropriating Arab women to allude to the struggle for democracy, and bridging them either as protagonists (to reaffirm local democracy) or victims (of a lack of democracy). Finally, we conclude that these discourses mine the feminist movement, nullifying the agency of these women and reinforcing patriarchal institutions.

\section{Key-words: Women - Arab Spring - Egypt - Decolonial Feminist Epistemology.}

\section{Introdução}

O estudo inicial deste trabalho foi realizado a partir de uma pesquisa bibliográfica que indagava sobrea complexidade da participação das mulheres nos protestos da chamada "Primavera Árabe" no Egito em 2011. Ao nos debruçarmos sobre fontes secundárias como trabalhos acadêmicos, artigos, reportagem e relatórios internacionais que abordavam a participação feminina nesses protestos, notamos que as mulheres eram, majoritariamente, representadas como "vítimas" ou "protagonistas". Destarte, este artigo pretende fazer uma análise epistemológica sobre a construção dessas narrativas, e para tal, articulamos teorias feministas que nos permitem iniciar uma discussão sobre a concepção de uma única Ciência e a construção do conhecimento.

A "Primavera Árabe", aqui mencionada, refere-se a uma série de revoltas e protestos nos países do Norte da África e Oriente Médio do começo da década de 2010. Nomeada assim pela mídia europeia e estadunidense fazendo alusão àquilo que os historiadores chamaram de "Primavera dos Povos" na Europa em 1848 , em que ocorreu, uma onda de protestos e revoltas das massas populares 
contra a maneira de governar em voga na época: as monarquias absolutistas (Hobsbawn, 1996).

Gomes (2011) fala sobre essa alusão da Primavera dos Povos como a "Primavera Árabe":

Em alguma medida é possível estabelecer analogias entre a Primavera de 1848 e as convulsões no mundo árabe. Em primeiro lugar, deve-se recordar que os anos 1846-1847 foram marcados pela baixa produção agrícola e por uma crise industrial que geraram escassez de alimentos e desemprego. Além disso, as populações dos países em que ocorreram levantes estavam submetidas a regimes autoritários e, em alguns casos, sujeitos à dominação estrangeira. Por fim, outro aspecto característico de 1848 foi a difusão do espírito de contestação por várias nações, o "efeito dominó" que transformou insurreições inicialmente localizadas em um acontecimento de grandes proporções. De modo análogo, a região atualmente em conflito [no Oriente Médio e Norte da África] sofre com os impactos de uma prolongada crise econômica mundial, com governos autoritários [...] (Gomes, 2011, p. 28 - grifo nosso).

O termo "Primavera Árabe" foi colocado debaixo do mesmo conceito "guarda-chuva" ao falar dos protestos que ocorreram nesses países africanos e árabes para aludir que os protagonistas de tais movimentos protestavam contra seus governos autocráticos - monarquias, ditaduras militares etc. Uma das maiores assimilações feitas, entretanto, é que a Primavera dos Povos foi uma tentativa de derrubar as monarquias absolutistas para implementar governos democráticos. Tal suposição nos parece uma falácia, uma vez que não houve alinhamento entre os protestos que ocorreram em diferentes países da Europa, muitos deles lutas de minorias étnicas, existindo um mal-estar quanto ao status quo, embora as ideologias políticas variassem entre socialistas, comunistas, liberais democráticos etc.

Neste sentido, com o termo "Primavera Árabe", há a tentativa de estampar a mesma narrativa para os protestos que ocorreram nesses países. Esse movimento fica evidenciado quando observamos artigos escritos para os maiores oligopólios midiáticos ocidentais e artigos acadêmicos, cujo objetivo é pontuar que os povos árabes estão finalmente conclamando o fim de governos autoritários para, enfim, implementarem uma democracia. Ranwsley (2011), em uma reportagem publicada no jornal britânico The Guardian, pontua: "eles querem o que nós temos no Ocidente: Estado de direito, direitos humanos, tribunais independentes, eleições livres e justas e um governo representativo. Com todas suas imperfeições, é a democracia liberal que eles almejam"2.

\footnotetext{
2 No original: "they want what we have in the west: rule of law, enforceable human rights, independent courts, free and fair elections and representative government. For all its imperfections, it is for liberal democracy that they yearn". (Rawnsley, 2011).
} 
É ainda mais saliente que, ao empreenderem este movimento de assimilar os protestos como outra "Primavera dos Povos", se utilizam do uso e da apropriação de um discurso feminista para validar essa luta pela democracia liberal aos moldes do Ocidente (Sjoberg \& Whooley, 2015; Abu-Lughod, 2002). Por conseguinte, faz-se necessária a análise da construção dessa narrativa que coloca a democracia como a única via para se estabelecer uma sociedade mais igualitária entre homens e mulheres; o Estado laico como a única opção para que as mulheres "árabes" não sejam mais oprimidas, assimilando a religião islâmica à opressão de gênero; e o "protagonismo" dessas mulheres nos protestos sob análise como prova irrefutável da luta por uma democracia liberal e laica.

Anterior à essa análise, é imprescindível refletirmos sobre a construção do saber para que possamos entender como, além da própria Ciência, as narrativas se tornaram um meio de colonização e perpetuação de um imaginário colonizado e binário. Começamos nosso artigo discorrendo sobre como a Ciência se tornou uma ferramenta aliada à colonização, em que o único saber possível é aquele feito pelo hegemon, tomando por aquela perspectiva como a única possível e inquestionável verdade, incluindo as teorias feministas. Assim, uma análise feminista decolonial se faz necessária para conseguirmos compreender, sob uma visão mais abrangente e menos moralista, as lutas políticas internas e de gênero de forma mais completa, além de apreender como se dá o papel das mulheres nos protestos de 2011 no Egito.

$\mathrm{Na}$ esteira desse raciocínio, demonstraremos na segunda parte, o que é a construção narrativa e como ela se deu na cobertura dos acontecimentos da "Primavera Árabe" no Egito, principalmente a relação que esta cobertura criou das mulheres egípcias como prova irrefutável da necessidade de uma democracia liberal aos moldes do Ocidente. Tal narrativa surge estampada tanto em discursos de empoderamento feminino dessas mulheres (invocando a imagem de que "antes" do fato, elas eram passivas e oprimidas por seus pares, pela sua religião e governo), quanto pelos discursos de que são as maiores vítimas dos protestos, sofrendo violência por parte do Estado (policiais e judiciário) e por parte dos egípcios (a favor e contra os protestos), numa tentativa de demonstrar que o fracasso em tornar tal Estado numa democracia é um perigo a mais para estas mulheres (Sjoberg \& Whooley, 2015).

Partimos desses dois discursos para demonstrar como a apropriação de uma narrativa feminista, superficial e colonial, acaba por minar o próprio 
movimento feminista, reforçando instituições patriarcais e coloniais. Explicitamos como tal apropriação é apenas mais uma ferramenta para justificar a colonização (dessa vez, de modos de pensar, políticos e de se socializar) e que vem sendo praticada desde a primeira onda de colonização dos europeus.

Apesar da diversidade do empoderamento político feminino no contexto dos protestos de janeiro de 2011 no Egito, essa visão orientalista sobre as mulheres egípcias pode ser influenciada por verdades, ditas absolutas, que fazem parte do senso comum em nossas sociedades ocidentais. É comum que nossa visão de mundo seja embasada em dicotomias e visões maniqueístas acerca das experiências - tal fato pode ser visto na construção de explicações e narrativas acerca da participação feminina nos protestos egípcios, por vezes como "vítima" ou como "protagonista" da mudança de uma sociedade dita retrógrada. Buscaremos elucidar, na terceira parte, como essa chave de entendimento que a coloca como vítima, passiva e sem poder de agência (powerless) e protagonista-objeto dentro das produções pode afetar negativamente a visão sobre a participação feminina nos protestos supracitados.

Portanto, a adoção de um único entendimento sobre os eventos em questão invisibiliza a luta feminista, o protagonismo e as violências sofrida por tais mulheres. De acordo com um relatório da Anistia Internacional de 2015, os ataques às mulheres durante os protestos capturaram a imaginação coletiva, entretanto

[...] tamanha violência não é confinada aos protestos. Hoje, a violência contra mulheres é prevalente no Egito, em suas casas, na esfera pública e na detenção. Os responsáveis incluem atores estatais, assim como não-estatais, companheiros, membros das famílias e pessoas desconhecidas que atacam nas ruas (Amnesty International, 2015, p. 5, tradução nossa) ${ }^{3}$.

Daí, pois, entendemos que embora denunciar as formas de violência sofridas demonstre o reconhecimento do problema, é preciso direcionar nosso foco para a forma como são (re)tratados e discutidos dentro das narrativas.

A concepção e a possibilidade de uma experiência feminina absoluta e compartilhada de vitimização ocultam outras versões da mesma história, ao mesmo tempo em que (re)afirmam a perspectiva de mulheres privilegiadas dentro dessa sociedade. A narrativa de uma história única de vitimização das mulheres egípcias cria estereótipos que transmitem apenas uma perspectiva

\footnotetext{
${ }^{3}$ No original: "however, such violence is not confined there. Today, violence against women and girls is prevalent in Egypt, in the home, in the public sphere and in detention. Those responsible include state actors, such as the security forces, as well as non-state actors, including spouses, family members and unknown assailants in the streets" (Amnesty International, 2015, p. 5).
} 
incompleta da história, mas que, se reproduzida continuamente, acaba por se tornar a única versão sobre o ocorrido.

\section{Epistemologia e decolonialidade}

As narrativas aqui utilizadas foram selecionadas exclusivamente por terem enfoque na participação das mulheres nos protestos no Egito em 2011. Ao analisá-las, entretanto, chamou-nos a atenção o fato de que ora caracterizavam a mulher como ator importante nos protestos para conclamar por maior autonomia e liberdade, ora como instrumentos utilizados pelas forças repressoras para calar os movimentos, utilizando-se da violência de seus corpos como principal meio.

A mulher foi encontrada apenas como objeto em ambas as análises, passível de escrutínio, mas não levando em conta suas próprias experiências como fonte importante de memória, de análise, e de agência ${ }^{4}$. Logo, entendemos como necessário proceder à investigação e à compreensão de o que querem dizer, de facto, os autores e autoras que estão escrevendo sobre essas mulheres sem Ihes dar espaço para contarem sua história.

Uma visão orientalista, pobre em análise e cega aos problemas intrínsecos à essas mulheres, que não são apenas vítimas da opressão por gênero, mas também do capitalismo e de sua história colonial, demonstra um discurso feminista branco e eurocêntrico, que apenas destaca a participação dessas mulheres sem tentar compreender todos os fatores que envolvem uma mulher não-branca, árabe, muçulmana, ex-colônia britânica etc. É, pois, necessário haver uma produção feminista decolonial, para que levemos em conta não apenas a mulher nesse movimento, mas suas experiências e memórias como um todo, como mulher num paradigma de colonização, nãoeuropeia, não-ocidental.

Para tanto, iremos investigar como essa visão dicotômica da realidade faz parte de uma construção da epistemologia hegemônica em voga, isto é, a Ciência moderna europeia que é dita como sendo a única com legitimidade acadêmica por ter seus "métodos científicos". Tal Ciência, pois, é um dos frutos da colonização - que não foi apenas um movimento econômico ou militar, mas também uma "conquista" sobre como enxergar o mundo e como acumular

\footnotetext{
4 Agência, no original: "theory of women's agency-i.e., an account of their capacity for individualized choice and action. [...] women might well choose to live differently were it not for the omnipresence of traditional heterosexual role models and media representations, not to mention the disadvantages of nonconformity" (Meyers, 2009).
} 
conhecimento. A não superação de visões colonizadas sobre o mundo implica a existência de discursos que bebem na construção dessa Ciência dando espaço a colonialidades, e podemos achá-los, inclusive, em narrativas que se dizem feministas, mas que ao invés de emancipar mulheres, emancipam apenas alguns tipos de mulheres, nominalmente aquelas conformadas na visão hegemônica.

Lugones (2010) afirma que a modernidade, fruto do capitalismo colonial moderno, opera numa lógica dicotômica que comporta apenas categorias separadas, especializadas e homogêneas; não sabendo, assim, compreender ou comportar as interseccionalidades inerentes à "mulher de cor" do terceiro mundo, que é, ao mesmo tempo, diversas "categorias" num corpo só. Esta chave dicotômica de entendimento prejudica uma análise mais complexa e abrangente do problema.

A violência sistêmica contra a mulher e o apagamento de sua agência esteve e está pautada na desigualdade de poder entre os gêneros de tal forma que afeta e impede sua participação plena na sociedade, especialmente na vida política e, ainda mais, na construção de sua própria narrativa.

Sendo assim, a construção de uma "Ciência" que está pautada na deslegitimação de outros saberes, marginaliza narrativas que não se tornam válidas por não obedecerem a métodos, regras etc. e, portanto, obedece e reforçam um sistema dominado por relações hierárquicas. Castro-Gómez argumenta que não vivemos mais num mundo em que existe a convivência de mais de um tipo de produção de saber; ao contrário, vivemos num mundo que o único saber aceitável é o científico e o resto dos saberes é eliminado (que ele chama de ponto zero):

agora todas as formas de conhecimento humano são ordenadas numa escala epistemológica de tradicional ao moderno, de bárbaros à civilização, de comunidade ao individual, do oriente ao ocidente [...]. Por meio dessa estratégia, o pensamento científico se posiciona como a única forma válida de produção de saber, e a Europa garante uma hegemonia epistemológica sobre todas as outras culturas do mundo (Castro-Gomez apud Tlostanova, 2011, p. 43, tradução livre $)^{5}$.

Nesse sentido, Lugones (2010, p. 743) chama de não-modernos aqueles que decidiram resistir ao moderno, especialmente suas categorias duais e

\footnotetext{
${ }^{5}$ No original: "now all forms of human knowledge are ordered on an epistemological scale from the traditional to the modern, from barbarism to civilization, from the community to the individual, from the orient to occident [...]. By way of this strategy, scientific thought positions itself as the only valid form of producing knowledge, and Europe acquires an epistemological hegemony over all other cultures of the world" (Castro-Gomez apud Tlostanova, 2011, p. 43).
} 
homogêneas. Foucault (2003) efetua um movimento similar quando fala sobre a construção da ciência e sua defesa da importância das genealogias.

Foucault fala sobre um conhecimento delinquente, um conhecimento científico "enterrado" e um conhecimento "inferior", "desqualificado" com "níveis abaixo da erudição científica" (2003, p. 7), que estava (re)surgindo para fundamentar críticas locais no que ele denominou de "produção teórica [de conhecimento] autônoma e descentralizada" (2003, p. 6). Ele afirma que ambos os conhecimentos explicitados - o enterrado e o desqualificado - foram marginalizados por serem conhecimentos de conflito (struggle), de combate, essencialmente um conhecimento adquirido pela memória bruta de lutas. Juntos, estes conhecimentos são as genealogias, essencialmente descontinuadas, locais, desqualificadas ou não legitimadas, "especificamente, anticientíficas" (2003, p. 9, grifo nosso).

Não por acaso, o conhecimento científico (a cientifização como uma instituição fundamental da modernidade) é construído como uma narrativa única e qualificada, centralizada e hierárquica, que, como todas as outras instituições, está embebida de poder e seu discurso de neutralidade é um posicionamento político. Nesse sentido, Alcoff afirma que: "a busca pela verdade será melhorada se nós chegarmos a uma melhor compreensão de como os domínios de conhecimento emergem, são limitados e restritos pelos jeitos peculiares em que conceitos são formados em momentos históricos diferentes" (Alcoff, 2011, p. 222, tradução livre) ${ }^{6}$

Haraway (1995), por sua vez, pontua o problema da construção epistemológica, que é "policiado por filósofos que codificam as leis canônicas do conhecimento" (p. 8). Segundo a autora, as feministas discutiram de forma extensa o problema da "objetividade" porque esta tem sido a maneira que eles, os cientistas, encontraram de mascarar a parcialidade que é inerente àquele que observa e escreve:

O "eles" imaginado constitui uma espécie de conspiração invisível de cientistas e filósofos masculinistas, dotados de bolsas de pesquisa e de laboratórios; o "nós" imaginado são os outros corporificados, a quem não se permite não ter um corpo, um ponto de vista finito e, portanto, um viés desqualificador e poluidor em qualquer discussão relevante. (Haraway, 1995, p. 7).

É compreensível a insistência da desconstrução do mito de universalidade e objetividade científica para que possamos validar discursos e

\footnotetext{
${ }^{6}$ No original: "The pursuit of truth will be enhanced if we come to a better understanding of how the domains of knowledge emerge, are delimited and constrained by the peculiar ways in which concepts are formed in different historical moments"(Alcoff, 2011,p. 222).
} 
narrativas que eram subjugados à classe de não-ciência e, portanto, desconsiderados totalmente. Como Haraway (1995) afirma: insistir na materialidade dos corpos que experienciam as observações, os acontecimentos e, acima de tudo, produzem o "saber local", é insistir para que possamos construir, validar e legitimar discursos e epistemologias factualmente feministas (Haraway, 1995), uma vez que "feminismo não é apenas um relato sobre a opressão das mulheres. Vai além disso ao fornecer materiais que habilitam mulheres a compreender suas situações sem sucumbir a elas" (Lugones, 2010, p. 747, grifo e tradução nossa) ${ }^{7}$.

Aqui, Lugones demonstra como não podemos reduzir o feminismo como opressão, porque isso implicaria ver a mulher sem agência, sem ferramentas para compreender e superar sua situação. Precisamos compreender os sujeitos que resistem como seres complexos, cuja categoria de "oprimido" apenas identifica parcialmente esse sujeito, isto é, ele tem mais camadas (layers) que apenas ser oprimido pela colonialidade de gênero: "Em nossa existência oprimida colonizada, racializada e de gênero, nós também somos algo além daquilo que o hegemon nos faz ser" (Lugones, 2010, p. 746 - grifo nosso). ${ }^{8}$

Esses sujeitos, pois, resistem; é pela resistência que uma tensão é criada, e apenas a partir dela que é produzida a libertação. Esta é ao mesmo tempo "adaptável e criativamente de oposição" (idem). Nesse sentido, tais sujeitos, ao resistirem, libertam-se e, por isso e a partir disso, se torna viável tanto o projeto decolonial quanto a possibilidade de identidade como grupo. Lugones insiste que é pela resistência que conseguimos superar nosso paradigma da colonialidade do gênero, descrito como "a análise da opressão racializada, capitalista, de gênero"9, isto é, a condição de gênero sendo indissociável ao capitalismo e a racialização. "Eu chamo de possibilidade de perpassar a colonialidade do gênero de 'feminismo decolonial" (Lugones, 2010, p.747) ${ }^{10}$.

Como pontua Butler (2016), há uma ideia errônea no senso comum de que vulnerabilidade e ação pressupõem que o paternalismo seja o local da ação e a vulnerabilidade apenas como "vitimização e passividade, invariavelmente

\footnotetext{
${ }^{7}$ No original: "feminism does not just provide an account of the oppression of women. It goes beyond oppression by providing materials that enable women to understand their situation without succumbing to it" (Lugones, 2010, p. 747).

${ }^{8}$ No original: "In our colonized, racially gendered, oppressed existences we are also other than what the hegemon makes us be" (Lugones, 2010, p. 746).

${ }^{9}$ No original: "the analysis of racialized, capitalist, gender oppression" (Lugones, 2010, p. 747).

${ }^{10}$ No original: "I call the possibility of overcoming the coloniality of gender 'decolonial feminism"' (Lugones, 2010, p. 747).
} 
lugares de inação" (p. 1) $)^{11}$. A dualidade já supracitada como o paradigma da modernidade é aqui, segundo as autoras, também encontrada na oposição de resistência e vulnerabilidade. O problema dessa oposição é que acaba reforçando estruturas paternalistas:

Ainda podem concluir que as mulheres estão numa posição impotente e, por isso, que homens estão sempre numa posição de poder. Como resultado, o ativismo feminista pode retornar as instituições políticas e sociais paternalistas, investindo estas instituições com o poder de realizar os objetivos feministas. (Butler, 2016, p. 2, tradução nossa) ${ }^{12}$.

O ponto crucial delas é que não podemos aceitar essa binarização de vítima (vulnerabilidade) e resistência, ignorando a potência de ação ou então as sujeições que todas as mulheres também podem sofrer por viverem num mundo capitalista, sexista e pós-colonial. As mulheres resistem apesar de sua vulnerabilidade, ou talvez por causa de sua vulnerabilidade.

\section{A construção de Narrativas e a Primavera Árabe - Egito, 2011}

A "virada linguística" se torna presente nos estudos de humanidades na segunda metade do século $X X$, chegando tardiamente às Relações Internacionais ao final dos anos 1980 para mostrar a necessidade de questionar os scripts de apreensão do mundo (Shapiro, 1989). Em outras palavras, incorpora-se nesses estudos a importância da construção da linguagem e das narrativas como parte fundamental da mensagem que se passa através delas, ou seja, como a própria linguagem, a escolha de palavras e a construção de uma narrativa demonstram parcialidade, tomada de posicionamento, ideologia etc.

Dessa forma, texto e linguagem não são apenas meios e formas de comunicação, como também são eles próprios os sentidos e significados que pretendem transmitir. Shapiro (1989) define, assim, a intertextualidade como a relação entre diferentes interpretações: o que produz a sua realidade textual, o significado. Nesse sentido, a realidade pode ser entendida como uma série de significados que não são naturais, mas sim impostos. Veremos como esse processo linguístico implica a construção da imagem das mulheres em questão.

Uma consulta a um dicionário nos mostrará que o termo "narrativa" é descrito como "narração; relato de um acontecimento ou fenômeno". Como

\footnotetext{
${ }^{11}$ No original: "victimization and passivity, invariably the site of inaction" (Butler et al, 2016, p. 1).

${ }^{12}$ No original: "Yet one might conclude that women are in a powerless position and, by implication, that men are always in a powerful one. As a result, feminist activism may turn to paternalistic political and social institutions, investing them with the power to realize feminist goals." (Butler et al., 2016, p. 2).
} 
argumentamos anteriormente, o autor não é neutro, nem desprovido de contexto social, político e biológico; ao contrário, o autor é parcial devido à sua história e experiência pessoal, suas posições políticas, ideológicas etc. (Haraway, 1995; Foucault, 2003). Portanto, ao relatar um evento, suas próprias percepções estarão implicadas e refletidas na construção e na forma do relato. A construção de uma narrativa é parcial e o modo como é constituída revela o que o autor quer expressar, para além do que está escrito: "enredos são dispositivos políticos que permitem a superação da fragmentação e a conquista de um desfecho discursivo" (Hajer apud Sjoberg \& Whooley, 2015, p. 266 - tradução livre $)^{13}$.

Aqui fica claro que a narrativa contém significados morais e de referências simbólicas no imaginário comum de quem a consome. A inserção e omissão do que está contido na narrativa, a escolha das palavras, o meio, os depoimentos coletados, tudo faz parte de um significado que não está propriamente explícito, mas que se faz presente de qualquer forma. Seu significado é compreendido por uma base comum, nominalmente a moral em que a narrativa está sendo contada, isto é, uma moral compartilhada por todo o seu público e, ainda, um imaginário comum compartilhado.

Como Sjoberg \& Whooley pontuam:

narrativas são atalhos que usamos para nos ajudar a compreender e consumir objetos e eventos, dada a infinidade de informações no mundo (Bordieu 1991; Khong 1992; Lakoff and Johnson 1980). [...] Os significados que as narrativas fixam não são aleatórios, mas são frequentemente estruturados por temas que garantem sua narração e moral, que ressaltam sua importância, "um conjunto de referências simbólicas que sugerem um entendimento comum" (Hajer 1995) [...] São estes conjuntos de referências simbólicas, ou "significações", que criam significados e permitem a aceitação e interpretação de estórias por diversos atores com diversas posições e interesses políticos, sociais e econômicos.(Sjoberg \& Whooley, 2015, p. 265-266, tradução livre $)^{14}$

As narrativas observadas tanto no meio acadêmico quanto no jornalístico-midiático sobre a chamada "Primavera Árabe" se utilizam da participação das mulheres nos protestos para demonstrar que há uma busca por

\footnotetext{
${ }^{13}$ No original: "story-lines are political devices that allow the overcoming of fragmentation and the achievement of discursive closure" (Hajer apud Sjoberg \& Whooley, 2015, p. 266).

${ }^{14}$ No original: "narratives are shortcuts that we use to help us comprehend and consume objects and events, given the infinite information in the world (Bordieu 1991; Khong 1992; Lakoff and Johnson 1980). [...] The meanings that narratives fix are not random but are often structured by themes that warrant their telling and morals, which underscore their importance, "a set of symbolic references that suggest a common understanding" (Hajer 1995). [...] It is these sets of symbolic references, or "significations," that create meaning and enable stories' acceptance and interpretation by diverse actors with diverse political, social, and economic positions and interests" (Sjoberg \& Whooley, 2015, p. 265-266).
} 
igualdade por parte delas, a qual só parece ser viável quando existe um governo democrático liberal e laico (Sjoberg \& Whooley, 2015). Seria, assim, apenas lógico que fosse esse o governo que os protestos estavam buscando.

Uma das reportagens de março de 2012 do New York Times tem como headline "Primavera Árabe Falha em Acalmar as Ansiedades das Mulheres" (Sweis, 2012) e pontua que mulheres de todo o mundo árabe estão com medo, por incertezas do que pode vir a ser o governo depois de derrubarem aquele que está no poder, citando que houve, sim, um aumento da "ideologia religiosa" e ainda que "por toda região, o aumento da ideologia política religiosa é uma ameaça aos direitos individuais" (Sweis, 2012) ${ }^{15}$. Fica claro, aqui, que a religião de forma politizada é vista como um risco, uma ameaça aos direitos das mulheres.

O imaginário comum que artigos como esse evocam é que os "países árabes", que em sua maioria têm o islamismo como religião oficial, apresentam essencialmente uma ameaça aos direitos das mulheres e, por conseguinte, lutar para que esses países religiosos se tornem uma democracia liberal significa uma luta feminista. Evocam, similarmente, um sentimento comum no Ocidente: que o islamismo é opressor com as mulheres, já que, por esses países serem religiosos, as mulheres têm menos direitos. $O$ artigo em questão se torna menos inibido conforme continua usando o depoimento de uma egípcia: "Eu fiquei chocada que os fundamentalistas tomaram o poder e eu não previ uma constituição masculina' ela [Ms. Bibars] disse, se referindo à vitória parlamentar da Irmandade Muçulmana no Egito e $28 \%$ dos assentos indo para partidos salafistas" (Sweis, 2012) ${ }^{16}$. Percebemos, pois, a construção de ideias de forma sutil, reafirmando imaginários por meio de referências simbólicas. Inclusive, essa não é a primeira vez em que aqueles com interesses na região se apropriam de um discurso feminista para defenderem que, a fim de salvar as mulheres oprimidas nessas regiões "retrógradas", há que se mudar ou apoiar a mudança dos detentores de poder (Abu-Lughod, 2002).

É tão proeminente a instrumentalização do papel das mulheres nesses protestos para corroborar uma mudança pela democracia, que desembocamos em duas narrativas que se complementam: uma, em que se enfoca a grande

\footnotetext{
${ }^{15}$ No original: "Across the region the rise of religious political ideology poses a threat to personal rights" (Sweis, 2012).

${ }^{16}$ No original: "I was shocked the fundamentalists took over and I did not foresee a male gender constitution,' she [Ms. Bibars] said, referring to the parliamentary election victory of the Muslim Brotherhood in Egypt and the 28 percent of seats that went to the more extreme Salafi parties" (Sweis, 2012).
} 
participação de mulheres nos protestos, uma prova do sucesso das "revoluções" e por si só uma evidência de democratização; outra, em que as mulheres foram as maiores vítimas, sofrendo durante e depois dos protestos, sendo assediadas por homens que protestavam, por forças militares repressoras, pelo sistema jurídico e pelo governo que se sucedeu ao levantamento, ainda mais autoritário e que ameaçava ainda mais os direitos das mulheres (Sjoberg \& Whooley, 2015). Ambas as narrativas associam de forma implícita a igualdade de gênero com a democracia; um governo teocrático como retrógrado; a religião islâmica como opressora.

$\mathrm{Na}$ verdade, essa percepção dos muçulmanos como retrógrados e opressores não é uma construção contemporânea, mas pode ser traçada à colonização, quando os europeus se utilizam da alteridade causada pelo contato para designar o "outro" de "atrasado", "bárbaro", "selvagem" etc., e que apenas sob a tutelagem dos europeus esse "outro" conseguiria alcançar a "civilidade", a "emancipação" e a "iluminação". Aliado a essa visão colonizada sobre o "outro" na abordagem das mulheres egípcias, o problema do liberalismo ocidental também está na sua apresentação como neutro, secular e descolado da cultura. A questão é que ele retira a legitimidade da religião na sociedade e a transforma em um sinalizador de subjugação do outro (Butler, 2008).

Além dessa separação clara entre o "self" europeu e o "outro" colonizado, Spivak ironiza outra forma de dividir para conquistar "homem branco salvando mulheres marrons de homens marrons" (apud Abu-Lughod, 2002, p. 784 tradução livre $)^{17}$. Isto é, os europeus apropriam-se de um discurso feminista em que chama a atenção para a opressão sofrida pela mulher para que, por meio da colonização, estas essas mulheres sejam "salvas" da opressão por parte de seus conterrâneos.

As mulheres orientais têm sido descritas na literatura Ocidental e nas mídias populares como figuras subservientes, sofrendo com opressões étnicas e religiosas. Essa ideia de sofrimento da mulher do Oriente Médio vem sendo utilizada como uma ferramenta retórica para acionar poderes Ocidentais a fim de resgatá-las e liberá-las dos valores conservadores do patriarcado Oriental (Ibroscheva, 2013, p. 872). Este movimento pode ser visto quando percebemos a mesma apropriação sendo usada na Guerra ao Terror ${ }^{18}$ para que, ao dirigir o

\footnotetext{
${ }^{17}$ No original "white men saving brown women from brown men" (apud Abu-Lughod, 2002, p. 784). ${ }^{18}$ Guerra ao Terror: "Guerra ao terror" ou "guerra ao terrorismo" são os dois nomes que o Presidente G. W. Bush usa para falar sobre as ações estadunidenses para responder aos ataques de 11 de setembro e que depois é utilizado por acadêmicos, jornalistas etc. para designar a luta global que os Estados Unidos lideram contra os terroristas - paradigma que vivemos até hoje. "This
} 
foco à mulher oprimida e submissa sob o regime do Talibã, apenas com a intervenção militar estadunidense é que essas mulheres seriam emancipadas:

[...] Seu discurso [de Laura Bush, primeira dama americana] reforça uma divisão profunda primeiramente entre "pessoas civilizadas do mundo", cujos corações se partem pelas mulheres e crianças afegãs, e o Talibã-e-os-terroristas, monstros culturais que querem, como ela coloca, "impor seu modo de ser ao resto do mundo". Mais revelador, o discurso conclama mulheres para justificar os bombardeios americanos e a intervenção no Afeganistão e fazer disso um exemplo para a "Guerra ao Terror" em que a intervenção está supostamente inserida. Como Laura Bush disse, 'Por causa dos nossos recentes ganhos militares na maior parte do Afeganistão, mulheres não estão mais aprisionadas em suas casas. Elas podem escutar música, ensinar suas filhas sem medo de serem punidas... A luta contra o terrorismo é também uma luta pelos direitos e dignidades das mulheres'(Abu-Lughod, 2002, p. 784, grifo nosso e tradução livre) ${ }^{19}$.

Aqui, percebemos dois movimentos concomitantes: a apropriação de um discurso feminista para angariar apoio para uma intervenção ou conquista militar; a associação do muçulmano - tanto regime de governo quanto cultura e sociedade - como opressor às mulheres que, vítimas como elas são, necessitam de ajuda para sair dessa situação. Além da nulidade de qualquer tipo de agência das mulheres desses países colonizados, principalmente os de religião muçulmana, esses discursos reforçam imagens e símbolos já comuns na nossa sociedade: o islã como opressor; a divisão aparentemente intransponível entre o Ocidente e o "resto" do mundo ainda bárbaro; o europeu-americano como baluarte da civilização e equidade de gênero (obviamente comparado a esses países considerados subdesenvolvidos) etc.

\section{O problema da assimilação da mulher como "vítima" ou "protagonista"}

Compreendida a construção da narrativa e de seus significados para além do texto em si, com todos os imaginários que provocam no público, passemos às duas narrativas que concernem às mulheres egípcias na chamada "Primavera Árabe". Como dito, observamos a tendência, já descrita por Sjoberg \& Whooley (2015), de que ora mostram as egípcias nos protestos como

crusade, this war on terrorism is going to take a while. And the American people must be patient. I'm going to be patient." (Bush, 2001).

${ }^{19}$ No original: "[...] her speech reinforced chasmic divides, primarily between the "civilized people throughout the world" whose hearts break for the women and children of Afghanistan and the Taliban-and-the-terrorists, the cultural monsters who want to, as she put it, "impose their world on the rest of us." Most revealingly, the speech enlisted women to justify American bombing and intervention in Afghanistan and to make a case for the "War on Terrorism" of which it was allegedly a part. As Laura Bush said, "Because of our recent military gains in much of Afghanistan, women are no longer imprisoned in their homes. They can listen to music and teach their daughters without fear of punishment... The fight against terrorism is also a fight for the rights and dignity of women". (Abu-Lughod, 2002, p. 784). 
evidência de uma luta pela democracia, ora como vítimas de todo o movimento, particularmente chamando a atenção para os diversos tipos de violência física que sofreram tanto por agentes do Estado quanto civis.

Ambas as narrativas retiram a subjetividade das mulheres - que constantemente são descritas como se fossem um grupo uno e homogêneo - e as colocam como objeto ou artifício a serem utilizados em prol da argumentação a que subjazem. Daí a razão de dizermos que tais narrativas anulam qualquer tipo de agência que estas mulheres poderiam ter. Sobre essa binarização, AbuLughod e El-Mahdi (2011) compartilham preocupações epistemológicas similares acerca das narrativas construídas e, principalmente, sobre a questão das mulheres na revolução,

Primeiro, essas narrativas assumem que as mulheres, de alguma forma, são passivas ou dormentes - nós queremos saber como elas de repente se tornam ativas na revolução [...]. Segundo, tais narrativas assumem um nível de especificidade de gênero com o qual me deixa desconfortável; é uma expectativa de que "mulheres" são um grupo homogêneo que tem um papel específico na revolução, desconsiderando o fato que diferentes grupos de mulheres participam de forma diferente, dependendo de seus lugares (tanto geográfico quanto de classe). Assume que há uma massa chamada 'mulheres egípcias'. (Abu-Lughod \& El-Mahdi, 2011, p. 684, tradução livre) ${ }^{20}$

Assim, evocamos a palavra "vítima" de forma deliberada, visto que há uma extensa discussão até nas próprias teorias feministas sobre o papel da mulher e o que vieram a cunhar como o termo de "vítima" ou "vitimização". Como pontua Stringer (2014), o termo passa a ter um aspecto negativo, de passividade, de falta de ação ou opção, vulnerável, de dependência etc., apagando o fato de que se existe vítima, esta é criada também por um contexto social, político, histórico e cultural. Esse movimento de obliteração do contexto que contribui para criar vítima(s) e a associação negativa com a palavra é chamado pela autora como "anti-victim talk", um movimento que não é só utilizado na academia, mas em praticamente todas as áreas sociais e de comunicação, tratando-se, portanto, de senso comum.

A assimilação da mulher como "vítima" é reducionista e homogeneizante, criando uma designação e compreensão de um único grupo vulnerável específico colocado em posição imutável e fixa. Resulta, assim, em respostas e formas de biopoder que são focalizadas na governança de condições da vida e

\footnotetext{
20 No original: "first, it assumes that women were somehow dormant or passive-we want to know how they suddenly became active in the revolution.[...] Second, it assumes a level of genderspecificity that I am uncomfortable with; it is expecting that "women" are a homogenous group that would have a specific role in the revolution, disregarding the fact that different groups of women might participate differently depending on their locations (both geographic and class-based). It assumes that there is a bulk called "Egyptian women"." (Abu-Lughod \& El-Mahdi, 2011, p. 684).
} 
gestão de populações (Hafez, 2012). O aparente foco na violência física, mais especificamente na humilhação que as mulheres árabes sofreram por agentes do Estado que, ao prenderem-nas, as forçaram a passar por um "teste de virgindade"21, também não é aleatório - ali é, pois, a prova irrefutável daquela sociedade tão diferente ser bárbara, incivilizada, até mesmo selvagem; as mulheres são vítimas dessa sociedade, dessa cultura e que precisam ser salvas. Vemos, pois, como a vitimização, infelizmente, pode ser enquadrada aos indivíduos como um traço des-empoderador, que retira a agência do ser vulnerável.

Assim sendo, dizemos que as narrativas que focam na violência sofrida pelas egípcias as relegam como "vítimas" justamente nesse sentido negativo e de passividade, porque anulam o contexto social, político e histórico que essas violências ocorrem - e que, de forma alguma, devem ser desconsideradas limitando-se a fazer a típica alusão de que as mulheres, em sua maioria muçulmanas e oprimidas, foram as "maiores vítimas" da "Primavera Árabe" tanto pelas violências sofridas nos protestos quanto pelas violências que virão a ser sofridas no governo que veio depois de Mubarak, militar e ultra-religioso. Elas são, nesse sentido, a metáfora escolhida para carregar o sofrimento dos povos que não se libertam pela via da democracia.

A problemática, pois, está na fixação e na permanência atribuídas a este papel, pois implicam diretamente a percepção e a construção da imagem delas como "vítima" des-empoderada, sem agência, incapaz de ação, em um rótulo incapaz de ser deslocado. A permanência dessa categoria - da "vítima" -, as (re)vitimiza e as recoloca em uma posição de um sujeito vulnerável desempoderado.

Vemos também como a violência contra os corpos foi utilizada como uma forma de coerção e coibição da participação das mulheres. A composição contextual na qual os protestos estavam inseridos possibilitou a exacerbação do patriarcado em uma sociedade machista, levando a um abuso exponencial de um poder já pré-existente e, consequentemente, a uma forma de punição das mulheres que ousaram participar e desafiar as normas de gênero a elas impostas através de assédios sexuais e estupros (Gerecke, 2010).

\footnotetext{
21 "Amnesty International has been told by women protesters that they were beaten, given electric shocks, subjected to strip searches while being photographed by male soldiers, then forced to submit to 'virginity checks' and threatened with prostitution charges. 'Forcing women to have a 'virginity tests' is utterly unacceptable. Its purpose is to degrade women because they are women,' said Amnesty International" (Amnesty International, 2011).
} 
Nesse sentido, faz-se importante ressaltar a condição corpórea da vulnerabilidade, pois todos os seres pactuam dessa fronteira comum - os corpos -, o que faz com que as formas de violência que operam na corporalidade sejam as primeiras sentidas. Desta forma, as mulheres que sofreram abusos e assédios contra seus corpos situaram e evidenciariam suas vulnerabilidades precariamente posicionadas através do corte de gênero e de classe (Butler, 2016). As narrativas fixando as mulheres como "vítimas" utilizam-se de uma perspectiva racional liberal, que tenta nos convencer de que essas mulheres poderiam ter controlado a susceptibilidade a essa vulnerabilidade corpórea, o que, consequentemente, gera a culpabilização da vítima simplesmente por sua presença nos protestos.

Entretanto, tais narrativas ocultam a resistência que é possível justamente pela sua posição de vulnerabilidade, isto é, a precariedade dos corpos que está inscrita na condição ontológica do ser permite, de certa forma, que a resistência possa existir. Os corpos permitem que haja uma forma de resistência que pressupõe essa vulnerabilidade (Butler, 2016). Assim, ter poder de agência não significa contornar a vulnerabilidade, mas, sim, demonstrar como todos estão situados ${ }^{22}$, porque as vítimas não necessariamente são passivas, podem, na verdade, arranjar força para resistir por causa de sua situação de vítima de um contexto.

Do outro lado, temos o discurso que apresenta a mulher egípcia nestes protestos como prova de que o movimento é, de fato, igualitário, em que mulheres e homens lutavam lado a lado, não havendo nenhuma separação ou divisão por gênero na busca pela democracia. Essa atenção em especial às mulheres não é um reconhecimento de alguma forma de agência dessas mulheres, mas sim da utilização das mesmas como medição por um país democrático: se elas estão nas ruas e não mais presas em suas casas oprimidas pela sua religião e sua família, é porque todos querem um regime novo de democracia. Apesar Winegar (2012), em seu artigo, ter certa sensibilidade quanto às nuances do protagonismo feminino, atentando-se para a diversidade das experiências femininas, ela não dá muita importância para a violência sofrida por elas ao escrever que "apesar das alegações (geralmente, mas não

${ }^{22}$ Situados: lócus, localização, posição, mas também de situação momentânea, passageira, e que pode ser perpassada. (Haraway, 1995). 
exclusivamente, verdadeiras) que não houve assédio sexual na praça Tahrir, muitas famílias têm medo da violência por gênero nas ruas da cidade" (p. 69) ${ }^{23}$.

Khamis (2011) é outro exemplo da forma rasa e a instrumentalização da participação dessas mulheres nos protestos como forma de medir uma luta pela democracia: destaca o protagonismo alegando uma suposta igualdade de gênero ao crer que as mulheres tiveram um papel notável e importante, e sua diversidade significou justamente "um novo momento de unidade, solidariedade e coesão, se espelhando em movimentos de bases igualitários que vieram a apoiar" (p. 692)24. Já Salama (2013), ao discutir a trajetória da significação do espaço público no Cairo, analisando os protestos na praça Tahrir, não disfarça sua assimilação simples da participação das mulheres com a democracia ao dizer que os protestos podem ser entendidos como um símbolo de democracia, liberdade e igualdade:

Islâmicos e liberais, muçulmanos e cristãos, mulheres e homens participaram de forma qualitativa da interação. Ricos e pobres, esquerdistas e direitistas, conservadores e liberais estavam todos unidos. Muçulmanos e cristãos faziam rezas em conjunto. Mulheres de diferentes contextos e códigos de vestimentas estavam engajadas em discursos políticos. Niqabs, hijabs, jeans e camisetas criaram juntos uma justaposição interessante que refletia a diversidade cultural na praça (Salama, 2013, p. 136, tradução livre) ${ }^{25}$

Tais excertos e posicionamentos demonstram como o tal "protagonismo" dado a essas mulheres nesses artigos não são parte de qualquer tipo de epistemologia feminista, principalmente por desconsiderar as perspectivas de gênero nessa sociedade, cultura, contextos histórico-social, e também os recortes de classe, de raça e religião dessas mulheres. Não há um protagonismo porque elas não são personagens, atores, cujas histórias são aprofundadas, as lutas ouvidas, os recortes compreendidos - é apenas a figura que mais apela para contar uma história: a que tais mulheres vivem oprimidas no regime (árabe, patriarcal, teocrático, muçulmano).

A divisão excludente entre vítima e protagonista, pois, não é suficiente nas análises dos protestos. Os corpos que participam de protestos articulam um

\footnotetext{
${ }^{23}$ No original: "despite the claims (generally but not exclusively true) that there was no sexual harassment in Tahrir, many families were afraid of gender-based violence in the streets of the city" (Winegar, 2012, p. 69).

${ }^{24}$ No original: "a new moment of unity, solidarity, and cohesion, mirroring the egalitarian, grassroots movement that they have come out to support" (Khamis, 2011, p. 692).

${ }^{25}$ No original: "Islamists and liberals, Muslims and Christians and men and women participated in a qualitative form of interaction. The rich and poor, political left and political right, and liberals and conservatives were all united. Muslims and Christians held joint prayers. Women with different backgrounds and dress code were engaged in political discourse. Niqabs, hijabs, jeans and T-shirts created together an interesting collage that reflected the social diversity in the square." (Salama, 2013, p. 136)
} 
discurso de dissidência, de resistência, de rechaçar o que é esperado deles dentro dessa sociedade. Os corpos performam novos significados e reinscrevem novos entendimentos do que o corpo de uma mulher dentro do espaço público supostamente teria a dizer ou significaria (Hafez, 2014). Se vieram a ser vítimas, que também ofereçamos a cortesia de ressignificarmos "vítima", de uma conotação negativa e passiva para uma de vítima com toda sua contextualização e poder de agência.

\section{Conclusão}

Iniciamos este artigo demonstrando como o termo "Primavera Árabe" faz alusão à "Primavera dos Povos" que a partir de um discurso feminista, raso e ocidental, entende que a única forma para se estabelecer uma sociedade mais igualitária entre os gêneros, seria através do alcance da democracia liberal.

Alicerçados em preocupações epistemológicas feministas decoloniais, propomos, analisar as produções acadêmicas e midiáticas acerca do papel das mulheres nos protestos que ocorreram no Egito em 2011. A relevância do debate se dá, pois, consubstanciada ao fato de que discussões de caráter epistemológico, feminista e decolonial vêm ganhando força nas Relações Internacionais nas últimas décadas. Portanto, entendemos que uma epistemologia feminista decolonial, pode oferecer insumos importantes para compreendermos como a consolidação de estruturas coloniais são perpetuadas até hoje através da construção dessas e outras narrativas.

Anterior ao movimento do enquadramento dessa análise, se fez imprescindível a problematização da concepção de uma única Ciência e de um saber universal, pois ao considerarmos um único "padrão" de conhecimento, outros saberes e experiências acabam sendo marginalizados, e assim também reforçamos relações hierárquicas de gênero, classe e raça. Nesse sentido, as formas de conhecimento não são óbvias e nem neutras; elas se transformam de acordo com a posição que o conhecedor ocupa e a partir de suas experiências plurais. Além da construção de um saber descolonizado para descortinar a complexidade da atuação das mulheres, julgamos ser impreterível adotar maneiras alternativas e não excludentes na produção do conhecimento.

À vista disso, precisamos sair da lógica dicotômica de exclusão para vermos como as mulheres, são seres complexos detentores de múltiplas camadas e que resistem de diferentes formas. Mesmo a partir de uma existência 
colonizada, racializada e genderizada, as mulheres ultrapassam a categoria "vítima". Como explicitado, a problemática da assimilação da mulher como ou "vítima" ou "protagonista" nessas narrativas está em seu caráter reducionista e homogeneizador, que não considera os cortes sociais, raciais e de gênero, a fluidez e o trânsito entre essas categorizações impostas. A condição da vítima não necessariamente anula seu poder de agência, e vice-versa.

Em suma, as dicotomias excludentes presentes nas narrativas supracitadas impedem a compreensão das interseccionalidades inerentes às mulheres e corroboram com a subalternização do papel delas nos protestos da Primavera Árabe no Egito, relegando-as a um segundo plano no qual sua presença, participação, protagonismo e sofrimento se resumem a uma instrumentalização a fim de (re)validar uma única versão sobre o evento que, não inesperadamente, reflete um imaginário colonizado.

\section{Referências Bibliográficas}

ABU-LUGHOD, Lila. Do Muslim women really need saving? Anthropological reflections on cultural relativism and its others. American Anthropologist, v. 104, n. 3, 2002, p. 783-790.

ABU-LUGHOD, Lila; EL-MAHDI, Rabab. Beyond the "Woman Question" in the Egyptian Revolution. Feminist Studies, v. 37, 3, 2011, p. 683-691.

ALCOFF, Linda M. Experience and Knowledge:The Case of Sexual Abuse Memories. In: WITT, Charlotte. Feminist Metaphysics: Explorations in the Ontology of Sex, Gender and the Self. Netherlands: Springer, 2011, p. 202223.

AMNESTY INTERNATIONAL. Egyptian Women Protesters Forced to Take 'Virginity Tests'.Disponível em:<https://www.amnestyusa.org/pressreleases/egyptian-women-protesters-forced-to-take-virginity-

tests/>. Acesso em: 15 nov. 2018.

Circles of Hell': Domestic, public and state violence against women in Egypt. Londres:

Amnesty International, 2015.

Disponível em : <https://www.amnestyusa.org/files/mde 120042015.pdf>.

Acesso em: 14 nov. 2018.

BUSH, George W. Remarks by the President Upon Arrival. September, 2001. The White House. Disponível em: <https://georgewbushwhitehouse.archives.gov/news/releases/2001/09/20010916-2.html>. Acesso em:

17 nov. 2018.

BUTLER, Judith. Introduction. In: BUTLER, Judith et al. Vulnerability in resistance. Durham and London: Duke University Press, 2016, p. 1-11. 
. Sexual politics, torture, and secular time. The British Journal of Sociology, v. 59, n. 1,2008 , p. $1-23$.

FOUCAULT, Michael. One: 7 January 1976. In:_. Society Must be Defended. Nova York: Picador, 2003, p. 1-22.

GERECKE, M. Explaining sexual violence in conflict situations. In: SJOBERG, Laura; VIA, Sandra. Gender, war, and militarism: feminist perspectives. Santa Barbara, CA: Praeger International, 2010, p. 138-154.

GOMES, Chiara A. A Primavera Árabe e as Lembranças de 1948. Breviário de Filosofia Pública. Número 9, 2011.

HOBSBAWM, Eric. "Revolutions". In: The Age of Revolution: 1789 1848. Vintage Books: Nova York, 1996.

KHAMIS, Sahar. The Arab "Feminist" Spring? Feminist Studies, v. 37, n. 3, 2011, p. 692-695.

HAFEZ, Sherine. The revolution shall not pass through women's bodies: Egypt, uprising and gender politics. The Journal of North African Studies, 2014, p. 172185.

HARAWAY, Donna. Saberes Localizados: a questão da ciência para o feminismo e o privilégio da perspectiva parcial. Cadernos Pagu, v.5, 1995, p 7-41.

IBROSCHEVA, Elza. The First Ladies and the Arab Spring: A textual analysis of the media coverage of the female counterparts of authoritarian oppression in the Middle East. Feminist Media Studies, v.13, n. 5, 2013, p. 871-880.

LUGONES, Maria. Toward a decolonial feminism. Hypatia, v.25, n.4, 2010, p. 742-759.

MEYERS, Diana T. Philosophical Feminism. Encyclopædia Britannica, 2009. Disponível em: <https://www.britannica.com/topic/philosophical-feminism>. Acesso em: 2 nov. 2018.

RAWNSLEY, Andrew. The west should cheer, not fear, this cry for freedom in Egypt. The Guardian, fev. 2011. Disponível em: $<$ https://www.theguardian.com/commentisfree/2011/feb/06/andrew-rawnsleyegypt-mubarak-democracy>. Acesso em: 14 nov. 2018.

SAID, Edward. Introdução. In: . Orientalismo: O oriente como Invenção do Ocidente. São Paulo: Cia das Letras, 2012.

SALAMA, Hussam H. Tahrir Square: A Narrative of a Public Space. International Journal of Architectural Research: ArchNet-IJAR, v. 7, n.1, 2013, p. 128-138.

SHAPIRO, Michael J. Textualizing Global Politics. In: DERIAN, James D; Shapiro, Michael. J. International/ Intertextual Relations: Postmodern Readings of World Politics. Lexington Books: New York, 1989, p. 11-22. 
SJOBERG, Laura; WHOOLEY, Jhonaton.The Arab Spring for women? Representations of women in Middle East politics in 2011. Journal of Women, Politics \& Policy, v.36, n. 3, 2015, p. 261-284.

STRINGER, Rebbeca. Introduction: feminism and victim politics in neoliberal times. In: Knowing Victims: Feminism, Agency and Victim Politics in Neoliberal Times. Londres/Nova York : Routledge, 2014, p. 1-16.

SWEIS, Rana F. Arab Spring Fails to Allay Women's Anxieties. The New York Times, $2012 . \quad$ Disponível em: <https://www.nytimes.com/2012/03/08/world/middleeast/arab-spring-fails-to-allaywomens-anxieties.html>. Acesso em: 8 nov. 2018.

TLOSTANOVA, Madina V. From Biopolitics and Necropolitics to Geo-Politics and Body-Politics of Knowledge. RUND Journal of Philosophy: Moscow, v. 23, n.1, 2011, p. 39-47.

WINEGAR, Jessica. The privilege of revolution: Gender, class, space, and affect in Egypt. Journal of the American Ethnological Society, v.39, n.1, 2012, p. 6770. 